\title{
KEARIFAN LOKAL MASYARAKAT DALAM PELESTARIAN LAHAN GAMBUT DI KECAMATAN SUNGAI KAKAP KABUPATEN KUBURAYA
}

(Community Local Wisdom of Peatlands Consevation in Sungai Kakap Sub-district of Kuburaya District)

\author{
Megawati, H. Sofyan Zainal, Burhanuddin \\ Fakultas Kehutanan Universitas Tanjungpura Pontianak. Jl. Daya Nasional Pontianak 78124 \\ Email : meggaw00@gmail.com
}

\begin{abstract}
Community local wisdom of peatlands conservation in Punggur Kecil villages is one form of community life culture in peserving peatlands for generation to generation. The purpose of this study is to examine the forms of local wisdom in preserving peatlands, analyzing the obstacles faced by the community in maintaining local wisdom as a supporter of peatland sustainability and analyzing and describing the community to have a role in peatland management. This research was condected in Punggur Kecil village Sungai Kakap sub-district Kuburaya Regency. This research was carried out for 2 weeks effectively in the field. The tools used include writing instruments, questionnaires, calculators, recording devices, cameras, and maps of research locations. The method used is a survey and observation method with direct interview techniques. Sampling is done by using purposive sampling. Based on the results of farming research is part of the local wisdom of Punggur Kecil village community which is also part of their cultural identity in addition to of course as an effort to meet food and economic needs of the family. The form of local wisdom of the people besides farming, namely by making ditches or regulating water systems. Land preparation by peasants on peatland land in traditional culture of the village community using long type machetes. Currently the biggest obstacle to peat is drainage and fires which are usually accompanied by forest conversion. Based on the results of field observations and discussions from the results of reserch conducted in general, the village community managed peatlands well. The results of the research conducted showed that all existing land management models use a mixed system. In the rice fields of the community, they combine rice plants with other holiculture plants such as chili, spinach, yams, leeks, bananas and other types of plants such as coconut, langsat and durian. Local community needs is obtained from agricultural products for their lively hood.
\end{abstract}

Keywords : Peatlands, Peatland conservation, Punggur Kecil Villages.

\section{PENDAHULUAN}

Lahan gambut adalah bentang lahan yang tersusun oleh tanah hasil dekomposisi tidak sempurna dari vegetasi pepohonan yang tergenang air sehingga kondisinya anaerobik. Material organik tersebut terus menumpuk dalam waktu lama sehingga membentuk lapisan-lapisan dengan ketebalan lebih dari $50 \mathrm{~cm}$. Tanah jenis ini banyak dijumpai di daerah-daerah jenuh air seperti rawa, cekungan, atau daerah pantai. Sebagian besar lahan gambut masih berupa hutan yang menjadi habitat tumbuhan dan satwa langka. Hutan gambut mempunyai kemampuan menyimpan karbon dalam jumlah yang besar. Karbon tersimpan mulai dari permukaan hingga di dalam tanah, mengingat kedalamannya bisa mencapai lebih dari 10 meter. Tanah gambut memiliki kemampuan 
menyimpan air hingga 13 kali dari bobotnya. Peranan gambut sangat penting dalam hidrologi, seperti mengendalikan banjir saat musim penghujan dan mengeluarkan cadangan air saat kemarau panjang. Kerusakan yang terjadi pada lahan gambut bisa menyebabkan bencana bagi daerah sekitarnya (Sagiman 2007).

Kearifan lokal adalah perilaku positif manusia dalam berhubungan dengan alam dan lingkungan sekitarnya bersumber dari nilai-nilai agama, adat istiadat, petuah nenek moyang atau budaya setempat yang terbangun secara alamiah dalam komunitas masyarakat untuk beradaptasi dengan lingkungan nya (Aminudin 2013). Kearifan lokal yang dimaksud adalah semua bentuk pengetahuan, keyakinan, pemahaman, atau wawasan serta adat kebiasaan atau etika yang menuntun perilaku manusia dalam kehidupan di dalam komunitas ekologis, semua bentuk kearifan lokal ini dihayati, dipraktikkan, diajarkan, diwariskan dari generasi ke generasi dan membentuk pola perilaku manusia terhadap sesama manusia, atau pun gaib (Odorlina 2015). Berladang merupakan sumber penghasilan utama masyarakat Desa Punggur Kecil, usahausaha pertanian ini menyangkut tanaman padi, jagung, dan buah-buahan. Sebagian dari hasil berdagang berternak ayam, sapi dan memelihara ikan. Cara bertani masyarakat masih dilakukan secara tradisional. Pengolahan lahan sangat bergantung dari kesuburan alami dari tanah yang menjadi lahan berladang, hasil berladang ini digunakan untuk kebutuhan hidup sehari-hari. Masyarakat menerapkan model agroforestry dan membudidayakan tanaman kelapa dan kopi di lahan gambut dan memiliki nilai ekonomi tinggi. Tanaman pinang juga cocok ditanam di lahan gambut sehingga pengelolaan agroforestry di lahan ini dapat memberikan multi manfaat. Upaya ini juga memberikan keuntungan ekonomis bagi masyarakat. Sistem parit yang dikembangkan pada masyarakat desa adalah sistem tertutup dengan menyebabkan keluar masuknya air terjadi pada saluran yang sama sehingga terjadi akumulasi senyawa beracun dan lumpur. Namun untuk menjamin siklus air tetap terjaga masyarakat membuat ketinggian lebih rendah dari pada tanggul dan ketinggian air pasang kecil ketika musim kemarau. Hal ini menyebabkan air masih dapat melimpasi bagian atas tabat dan masuk ke anak parit. Menurut petani Desa Punggur Kecil mereka beranggapan bahwa air gambut merupakan racun bagi tanaman sehingga harus dibuang dan mengalirkannya. Masyarakat untuk mengalirkannya membuat saluran air atau parit yang dalamnya 2 meter setengah, setelah datang air hujan maka parit akan ditutup. Tujuan penelitian ini adalah mengkaji bentuk-bentuk kearifan lokal masyarakat dalam menjaga kelestarian lahan gambut, menganalisis hambatanhambatan apa saja yang dihadapi masyarakat dalam menjaga kearifan lokal sebagai penunjang kelestarian lahan gambut, menganalisis dan mendiskripsikan masyarakat untuk memiliki peran dalam pengelolaan lahan gambut.

\section{METODE PENELITIAN}

Waktu, Alat dan Obyek Penelian

Penelitian dilaksanakan di Desa Punggur Kecil Kecamatan Sungai Kakap Kabupaten Kuburaya. Penelitian dilakukan 
selama 2 minggu efektif di lapangan. Alat dan bahan yang digunakan dalam penelitian ini adalah :

1. Alat tulis menulis, digunakan untuk mencatat data yang ada dilapangan.

2. Kuesioner (daftar pertanyaan), digunakan untuk sebagai alat bantu dalam pengumpulan informasi atau data.

3. Kalkulator, digunakan untuk menghitung data.

4. Alat perekam.

5. Kamera, untuk mendokumentasikan obyek penelitian.

6. Peta lokasi penelitian, untuk menunjukkan lokasi penelitian.

Obyek yang diteliti dalam penelitian ini adalah masyarakat Desa Punggur Kecil Kecamatan Sungai Kakap Kabupaten Kuburaya. Obyek penelitian ini dipilih karena masyarakatnya masih mempertahankan lahan gambut yang telah ada dan dikelola secara turun temurun.

\section{Pengumpulan Data}

Data yang dikumpulkan dalam penelitian ini meliputi data primer dan data sekunder.

1. Data Primer

Merupakan data yang diperoleh dengan wawancara langsung dengan masyarakat sebagai responden yang dijadikan obyek penelitian dengan bantuan daftar pertanyaan (kuesioner) ataupun pedoman wawancara yang telah disiapkan. Data primer dalam penelitian ini adalah bentuk-bentuk kearifan lokal masyarakat dalam pelestarian lahan gambut, hambatan masyarakat dalam menjaga kearifan lokal sebagai penunjang kelestarian lahan gambut serta karakteristik masyarakat dalam memiliki peran pengelolaan lahan gambut.

2. Data Sekunder

Data sekunder adalah data yang diperoleh dari sumber kedua yang bersifat penunjang seperti dari instansi, badan atau lembaga dan literatur. Data tersebut meliputi keadaan umum lokasi, foto, catatan dan rekaman.

\section{Teknik pengumpulan data}

Teknik pengumpulan data melalui observasi, wawancara dan dokumentasi dengan alat bantu berupa pedoman wawancara atau kuesioner, catatan observasi, kamera, dan alat tulis menulis. Pengelolaan data yang dikumpulkan melalui tahapan klasifikasi dan interprentasi data dan selanjutnya teknik pengumpulan responden untuk keperluan penelitian dilakukan secara purposive sampling, yaitu salah satu teknik sampling non random sampling dimana peneliti menentukan pengambilan sampel dengan cara menetapkan ciri-ciri khusus yang sesuai dengan tujuan penelitian sehingga diharapkan dapat menjawab permasalahan dalam penelitian.

\section{Analisis Data}

Analisis data yang digunakan dalam penelitian ini menggunakan pendekatan deskriptif kualitatif. Analisis deskriptif adalah sebuah metode penelitian yang digunakan untuk menganalisis data dengan cara mendiskripsikan atau menggambarkan data yang telah terkumpul tanpa bermaksud membuat kesimpulan yang berlaku untuk umum atau generalisasi (Kurniawan 2015). Analisis deskriptif disebut juga sebuah metode penelitian yang digunakan untuk mendiskripsikan suatu peristiwa yang 
terjadi pada saat sekarang atau masalah aktual. Penelitian analisis deskriptif bertujuan untuk mendeskripsikan atau menggambarkan secara sistematik mengenai fakta-fakta yang berhubungan antara fenomena yang diselidiki dan bukan angka. Data yan dianalisis adalah data primer yang telah terkumpul dari pengamatan lapangan dan data sekunder mengenai kondisi penelitian.

\section{Populasi dan Sampel}

Populasi dalam penelitian ini adalah masyarakat Desa Punggur Kecil Kecamatan Sungai Kakap Kabupaten Kuburaya. Responden yang diambil dari masyarakat adalah kepala keluarga yang berada di Desa Punggur Kecil yang berusia minimal 20 tahun keatas serta sehat jasmani dan rohani serta sudah menetap minimal 5 tahun. Jumlah sampel yang diambil untuk penelitian disesuaikan dengan jumlah populasi yang ada dilapangan. Menentukan besarnya ukuran sampel di gunakan rumus Slovin dipergunakan Hasan (2000) dan Rachmawaty $d k k$ (2006) sebagai berikut : $\mathrm{n}=\frac{N}{1+N e 2}$

Dimana :

$\mathrm{n}=$ Ukuran Sampel.

$\mathrm{N}=$ Ukuran Populasi.

$\mathrm{e}=$ Persen kelonggaran tingkat ketelitian yang diinginkan (dalam penelitian ini adalah 10\%).

Tabel 1. Jumlah Kepala Keluarga Setiap Dusun dan Jumlah Sampel Setiap Dusun di Desa Punggur Kecil Kecamatan Sungai Kakap Kabupaten Kuburaya. (The number of households in each hamlet and number of samples in each hamlet in the Punggur Kecil, Sungai Kakap district, Kuburaya district)

\begin{tabular}{ccc}
\hline No. Dusun & Jumlah KK & Jumlah Sampel \\
\hline 1. Kenanga & 314 & 58 KK/Dusun \\
2. Nusa Indah & 88 & 16 KK/Dusun \\
3. Cempaka Putih & 42 & 8 KK/Dusun \\
\hline Total & 444 & $81,61=82$ KK/Dusun \\
\hline
\end{tabular}

$\mathrm{n}=\frac{444}{1+444 \cdot(0.10) 2}=81,61 \approx 82 \mathrm{KK}$

Berdasarkan perhitungan jumlah sampel populasi (kepala keluarga) $444 \mathrm{KK}$ dengan tingkat kesalahan $10 \%$ yaitu sebesar 81,61 dan untuk mempermudah dalam perhitungan maka sampel tersebut dibulatkan menjadi $82 \mathrm{KK}$.

Jumlah sampel yang diambil untuk penelitian sebanyak $82 \mathrm{KK}$ yang tersebar di tiga dusun. Agar sampel yang diambil dapat melalui jumlah populasi yang ada, maka teknik penentuan jumlah sampel pada tiap dusun di tentukan dengan rumus distrafikasi (Geokaryawi 1995) sebagai berikut :

$\mathrm{A}=\frac{B}{C} \times D$

Dimana :

$A=$ jumlah sampel tiap dusun

$\mathrm{B}=$ jumlah sampel yang diinginkan

$\mathrm{C}=$ jumlah populasi tiap dusun

$\mathrm{D}=$ jumlah populasi secara keseluruhan.

Hasil perhitungan rumus distribusikan maka diperoleh jumlah sampel pada setiap dusun adalah sebagai berikut :

Dusun kenanga $=\frac{314}{444} \times 82=58$

Dusun Nusa Indah $\quad=\frac{88}{444} \times 82=16$

Dusun Cempaka Putih $=\frac{42}{444} \times 82=8$

Guna lebih jelas jumlah sampel dari setiap dusun di sajikan pada tabel 1. Berikut ini : 


\section{HASIL DAN PEMBAHASAN Identitas Responden}

Identitas responden diambil berdasarkan tingkat umur, jenis kelamin, tingkat pendidikan, dan berdasarkan jenis pekerjaan responden. Umur responden dalam penelitian ini tidak ditentukan karena dalam penelitian ini responden yang dipilih bukan berdasarkan umur tetapi berdasarkan siapa saja masyarakat yang masih tetap melakukan pelestarian lahan gambut. Tingkat pendidikan masyarakat yang dijadikan sebagai responden cukup bervariasi yaitu mulai dari pendidikan Sekolah Dasar (SD) sampai dengan tingkat Sekolah Menengah Atas (SMA). Berdasarkan hasil penelitian yang dilakukan di lapangan tentang kearifan lokal masyarakat dalam pelestarian lahan gambut di Desa Punggur Kecil telah mendapatkan responden sebanyak 82 orang yang saat ini masih tetap melakukan pelestarian lahan gambut.

\section{Bentuk-bentuk Kearifan Lokal Masyarakat Dalam Pelestarian Lahan} Gambut

Berdasarkan hasil penelitian melalui wawancara yang dilakukan dilapangan di Desa Punggur Kecil telah mendapatkan responden sebanyak 82 orang yang saat ini masih melakukan kearifan dalam pelestarian lahan gambut. Bentuk-bentuk kearifan lokal masyarakat antara lain :

1. Berladang/bertani

Berladang adalah bagian dari kearifan local masyarakat Desa Punggur Kecil yang juga merupakan bagian dari identitas budaya mereka selain tentu saja sebagai upaya untuk mencukupi kebutuhan pangan dan ekonomi keluarga. Masyarakat desa yang mayoritas kawasannya adalah gambut memiliki model pemanfaatan lahan yang tetap menjaga kelestarian lahan gambut. Sejak dulu masyarakat desa menerapkan model pertanian agroforestry (wanatani), atau suatu bentuk pengelolaan hutan atau pohon kayu-kayuan dengan penanaman komoditas atau tanaman jangka pendek seperti tanaman pertanian. Masyarakat memiliki pengetahuan dan teknologi local dalam mengelola lahan gambut sehingga kelestariannya tetap terjaga.

Masyarakat menerapkan model agroforestry dan membudidayakan tanaman kelapa dan kopi di lahan gambut dan memiliki nilai ekonomi tinggi tanaman pinang juga cocok ditanam di lahan gambut sehingga pengelolaan agroforestry di lahan ini dapat memberikan multi manfaat. Masyarakat selain tetap menjaga kelestarian gambut, upaya ini juga memberikan keuntungan ekonomis bagi para petani.

2. Pembukaan Parit

Bentuk kearifan lokal masyarakat Desa Punggur Kecil selain bertani/berladang yaitu dengan cara membuat parit atau pengaturan tata air. Pengetahuan ini dikembangkan dalam kurun waktu yang lama. Salah satu komponen penting dalam pengaturan tata air lahan gambut adalah bangunan pengendali berupa pintu air disetiap saluran. Masyarakat desa sudah menguasai teknologi ini yaitu melalui sistem tabat yang berfungsi 
mempertahankan keberadaan air dengan mencegah air keluar sewaktu surut tetapi sewaktu pasang air dapat mudah masuk.

Sistem parit yang dikembangkan oleh masyarakat desa adalah sistem tertutup dengan menyebabkan keluar masuknya air terjadi pada saluran yang sama sehingga terjadi akumulasi senyawa beracun dan lumpur. Guna untuk menjamin siklus air tetap terjaga masyarakat membuat ketinggian lebih rendah dari pada tanggul dan ketinggian air pasang kecil ketika musim kemarau. Hal ini menyebabkan air masih dapat melimpasi bagian atas tabat dan masuk ke anak parit. Sistem pengelolaan tata air yang dikembangkan mengedepankan aspek kerjasama kelompok dan solidaritas, hal ini mengingat air merupakan sumber daya yang dibutuhkan bersama guna menunjang produktivitas mereka.

3. Penyiapan Lahan dan Pengolahan Tanah

Penyiapan lahan oleh petani di lahan gambut dalam budidaya tradisional masyarakat desa menggunakan tajak sejenis parang panjang. Parang panjang digunakan untuk menebas rumput dan berfungsi juga sebagai alat untuk membalik tanah.

\section{Hambatan Masyarakat Dalam Pengelolaan Pelestarian Lahan Gambut}

Berdasarkan hasil wawancara (survei) dengan beberapa responden, mereka mengatakan selama ini kendala atau hambatan masyarakat dalam pengelolaan pelestarian lahan gambut adalah kekeringan dan kebakaran.
Masyarakat kurang menyadari, kurang tahu, dan kurang memahami bagaimana pentingnya menjaga kelestarian gambut agar dapat bermanfaat dengan baik. Kendala masyarakat sekitar juga disebabkan karena selama ini kurangnya warga di sekitar Desa untuk mengikuti penyuluhan/pelatihan dari pemerintah yang mengadakan kegiatan atau penyuluhan tentang bagaimana pentingnya menumbuhkan rasa kepedulian masyarakat terhadap pelestarian lahan gambut.

Karakteristik Masyarakat Dalam Pengelolaan Lahan Gambut

Interaksi mereka yang cukup lama dan intensif dengan jenis tanah ini melalui pengamatan serta trial error (coba-coba) telah berkembang berbagai pengetahuan yang menjadi kearifan lokal petani pada masing-masing komunitas penggarap lahan gambut. Beberapa kegiatan pengelolaan lahan gambut yang telah dikembangkan oleh masyarakat Desa yaitu :

1. Usaha masyarakat dalam meningkatkan kesuburan lahan gambut yaitu menggunakan abu sisa kebakaran lahan gambut pada musim kemarau atau memang membuat abu dari pembakaran gulma dan sisa-sisa tanaman.

2. Usaha masyarakat dalam menghindari terjadinya kebakaran, daerah-daerah yang telah memanfaatkan lahan gambut secara intensif mengupayakan penanggulangan kebakaran lebih banyak dilakukan secara individual oleh masing-masing pemilik lahan. 
Petani membuat tempat khusus (pondok) untuk membakar gulma dan sisa-sisa tanaman. Masyarakat juga membuat parit-parit disekeliling lahab agar lahan selalu berair sehingga tetap basah dan dapat terhindar dari kebakaran.

3. Menurut para petani tidak semua tanaman cocok ditanam di lahan gambut. Petani melakukan pemilihan jenis tanaman yang disesuaikan dengan kondisi ketebalan gambut. Penentuan jenis tanaman yang dianggap cocok dengan kondisi lahan pada awalnya dilakukan secara cobacoba.

Terdapat suatu kebiasaan petani lahan gambut di Desa Punggur Kecil untuk membakar sisa panen dan serasah. Hal ini dilakukan karena abu sisa pembakaran oleh petani dinilai sebagai penyubur lahan yang penting dalam bercocok tanam di lahan gambut. Pembakaran hanya dilakukan pada lapisan permukaan gambut yang masih mentah dan kasar dengan kedalaman $5 \mathrm{~cm}$.

Masyarakat desa sudah aktif bertani seperti menanam padi dengan menggunakan cara yang baik. Cara ini dikarenakan masyarakat telah mengerti dengan kebutuhan mereka sehingga masyarakat memaksimalkan produktivitas lahannya. Sistem pertanian juga dilakukan oleh masyarakat tetapi hanya sebagian saja. Tanaman pertanian yang yang ditanam masyarakat ialah padi.

Sistem pengelolaan sawah tidak bisa lepas dari setiap wilayah, Desa Punggur
Kecil juga mengelola sistem pertanian. Sistem pertanian yang dilakukan ialah menanam padi, padi merupakan tanaman pokok untuk kehidupan. Menurut Soewadji (2012) mengungkapkan bahwa pola pengelolaan lahan yang dilakukan masyarakat Baduy adalah dengan menanam tanaman pangan dengan palawija. Keadaan ini hampir sama dengan pola pengelolaan masyarkat Desa Punggur Kecil, hanya terdapat sedikit perbedaan antara masyarakat Punggur Kecil dan Baduy yaitu pengelolaan lahan sawah di Desa Punggur Kecil tidak menggunakan sistem ladang berpindah dan masa berpindah di Baduy 5 tahun sekali.

\section{Kesimpulan}

1. Berladang bagian dari kearifan lokal masyarakat desa yang merupakan untuk mencukupi kebutuhan pangan dan ekonomi, masyarakat desa menerapkan model pertanian agroforestry (wanatani). Saat membuka lahan masyarakat Desa Pungur Kecil menggunakan tajak sejenis parang panjang yang digunakan untuk menebas rumput dan berfungsi sebagai alat membalik tanah.

2. Kebiasaan masyarakat dalam mengatur pengelolaan air lahan gambut biasanya membuat parit untuk mempertahankan ketebalan lapisan gambut dilahan usaha taninya.

3. Hambatan masyarakat desa saat ini adalah pengeringan dan kebakaran serta kurangnya kesadaran warga untuk 
penyuluhan/pelatihan dari pemerintah dalam kegiatan seputar pelestarian lahan gambut.

\section{Saran}

Mempertahankan kearifan lokal yang baik salah satu caranya yaitu dengan pemberdayaan komunitas yang berbasis kearifan lokal yaitu sebuah upaya perubahan yang dilakukan oleh anggota dari komunitas itu sendiri. Para anggota merumuskan masalah, menyusun rencana lalu menentukan arah perubahan-perubahan sesuai dengan keyakinan yang mereka miliki dalam kearifan lokalnya.

Menurut petani Desa Punggur Kecil mereka beranggapan bahwa air gambut merupakan racun bagi tanaman sehingga harus dibuang. Padahal ini bukanlah pengelolaan gambut yang baik, gambut tidak boleh terlalu kering karena apabila gambut mengalami kekeringan maka gambut akan rusak dan menimbulkan emisi gas rumah kaca yang tinggi. Oleh karena itu untuk kebutuhan budidaya perlu dibuat canal bloking yang dilengkapi dengan pintu air guna menyalurkan kelebihan air hingga batas yang tidak membuat gambut mengalami degradasi akibat terjadi kekeringan.

\section{Ucapan Terimakasih}

Dengan selesainya penelitian ini saya mengucapkan terima kasih kepada Kepala Desa Punggur Kecil Kecamatan Sungai Kakap Kabupaten Kuburaya, pak
Abdullah selaku ketua RT di dusun Mawar serta seluruh masyarakat Desa Punggur Kecil yang telah memberikan motivasi dan bantuan dalam pelaksanaan penelitian ini sehingga terlaksana dengan baik, lancar dan sukses.

DAFTAR PUSTAKA

Aminuddin. 2013. Menjaga Lingkungan dengan Kearifan Lokal. Titian Ilmu. Bandung Wartarimba

Geokaryawi. 1995. Manajemen Laba Teori dan Model Empiris. Jakarta: Grasindo

Hasan. 2000. Teknik Sampling. Bandung: Alfabeta

Kurniawan, W. 2015. Dampak Sosial Ekonomi Pembangunan Pariwisata Umbul Sidomukti Kecamatan Bandungan Kabupaten Semarang. Skripsi. Fakultas Ekonomi Universitas Negeri Semarang

Odorlina R. 2015. Balai Penelitian Kehutanan Aek Nauli. Indonesia

Rahmawaty, dkk. 2006. Pengaruh Asimetri Informasi terhadap Praktik Manajemen Laba pada Perusahaan Perbankan Publik yang terdaftar di Bursa Efek Jakarta

Sagiman Saeri. 2007. Pemanfaatan Lahan Gambut dengan Perspektif Pertanian Berkelanjutan

Soewadji, J. 2012. Pengantar Ilmu Metedologi Penelitian. Jakarta : Mitra Wacana Media 